\title{
Performance and Welfare Status of Working Donkeys
}

\author{
Girma Gebresenbet $^{1}$, Samuel Aradom ${ }^{1}$ and Pascal Gitari Kaumbutho ${ }^{2}$ \\ 1. Department of Energy and Technology, Swedish University of Agricultural Sciences, P.O. Box 7032, SE-750 07 Uppsala, Sweden \\ 2. Network for Draught Animal Technology, Kenya Network for Dissemination of Agricultural Technologies (KENDAT), P.O. Box \\ 2859-00200, Nairobi, Kenya
}

\begin{abstract}
In Africa, donkeys have significant contribution in traction operation, but there is little research related to workload and their welfare. The objective of this work was to examine the effect of various loads on donkeys' physiological and behavioural responses to evaluate welfare. Donkeys weighing of 132-172 kg (159 $\pm 11 \mathrm{~kg})$ and totally 20 were used for the experiment. The experimental design included two wheeled cart $\times$ seven load class (an increment of $100 \mathrm{~kg}$ ) with five repetitions each, and the travelled distance was $2 \mathrm{~km}$. Travelled time, behavioural occurrences and physiological responses were recorded. Statistical analysis was conducted using SAS (version 9.4) software programme. When loads were 500-700 kg, heavy and rapid panting and falling down occurred frequently. When loads increased successively and reached 500, 600 and $700 \mathrm{~kg}$, speed started declining from $3.68 \mathrm{~km} / \mathrm{h}$ to 3.5, 2.94 and $2.54 \mathrm{~km} / \mathrm{h}$, respectively, indicating that speed and applied loads are inversely correlated $(P<0.001)$. Heart rate was 129 $\pm 11 \mathrm{bpm}$ at $700 \mathrm{~kg}$, and in respect to resting state, donkeys' heart rate elevated by a factor of up to 3 . As the load exceeded $400 \mathrm{~kg}$, the speed declined significantly, and behavioural occurrences like heavy panting and falling down confirmed this. This leads to the conclusion that donkeys could pull about 2.7 times of their live weight. But if they have continuous and long working hours (about 6 h), it is recommended to keep load of two wheeled cart about double of donkeys live weight so as to safe guard donkeys' welfare.
\end{abstract}

Key words: Donkey, load, behaviour, heart rate, welfare.

\section{Introduction}

The estimate world donkey population has steadily increased from 37 million in 1961 to 44 million in 1996, but it is not evenly distributed around the world with most donkeys occurring in semi-arid and mountainous areas. In Africa, in the last fifty years (1949-1996), donkey population has increased from 8.5 million to 13.7 million [1]. The great majority of donkeys in the world are kept specifically for work. Their most common role is for transport, whether riding, pack transport or pulling carts. They may also be used for farm tillage. In certain countries, they may assist threshing, raising water, milling or other operations [2].

In most of Africa, animal power is being used to replace or supplement for human power, and this trend is continuing in most of the continent. With so many agricultural and transport tasks performed by humans,

Corresponding author: Girma Gebresenbet, professor, research fields: animal logistics and transport. there is much scope for continued expansion. In many countries, women use donkeys for pack transport and sometimes for riding [3]. In Africa, while motorized transport has been thriving rapidly since the 20th century, the use of animal power for local transport has not experienced a proportionate decline [4]. Donkeys are preferred as draught and transport animals, because they are friendly, hardy, quiet and more economical, compared to horses and oxen. They can be maintained on local farm produce, and are easy to train, intelligent and patient while working [5]. These characteristics make donkey a likely choice for many children and women to use in developing countries [6].

Donkeys as pack animals can carry a load that is up to $100 \mathrm{~kg}$ or that is $50 \%$ of their body weight [7]. It has also been reported that donkeys can carry heavy loads twice of the weight that a person can carry for a longer distance [8]. As donkeys become a more popular choice of work animals for small-holder 
farmers, specific management practices need to be devised in order to fully maximize their natural survival advantages [9].

The improvement in health and welfare will enhance their productivity and provide their owners with a more reliable source of income [10]. Improper housing and handling expose donkeys to wounds and lead to poor performance. Donkeys are exposed to wound infections mostly during the hot-dry and rainy seasons [11]. Various welfare issues have been reported in working donkeys elsewhere in Africa. Long working hours, harsh environmental conditions, over-use, improper equipment, limited veterinary attention and little or poor quality supplementary feed during dry periods can lead to welfare problems [12-15].

Changes in heart rate, breathing rate and temperature are the most important physiological responses to work and can be measured on working animals without causing them too much discomfort $[16,17]$.

It is difficult to measure welfare and feelings of an animal. However, it is possible to get some indication of what the animal is feeling by indirect means through its physiological and behavioural responses. Behaviour is the expression of an animal's perception and interaction with its environment $[18,19]$.

Despite the large donkey population and significant contribution in traction operation, little research has focused on donkey in respect to workload and the related stress that would contribute to improving welfare and efficiency. Thus, the main objective of this work was to study the effect of various loads on donkeys' physiological and behavioural responses to evaluate welfare during work.

\section{Materials and Methods}

\subsection{Animals and Loads}

The field experiment was conducted in the outskirt of Nairobi during the long rainy season in April. During this month, the average rainfall was $130 \mathrm{~mm}$ and temperature varied between $15{ }^{\circ} \mathrm{C}$ and $25{ }^{\circ} \mathrm{C}$, whereas relative humidity was around $60 \%$. Donkeys weighing between $132 \mathrm{~kg}$ and $172 \mathrm{~kg}$ with mean weight $159 \pm 11 \mathrm{~kg}$ were used for the field experiment and the total number of animals was 20 . The donkeys were subjected to pulling two wheeled carts having varying loads.

The loads successively increased by $100 \mathrm{~kg}$ from $100 \mathrm{~kg}$ to $700 \mathrm{~kg}$ forming seven load groups. Therefore, the experimental design included two wheeled cart $\times$ seven load class with five repetitions each. Travelled distance was $2 \mathrm{~km}$ for all field measurements. In order to avoid heat stress, the measurements were performed at 08:00 and 16:00 local time.

\subsection{Behavioural Observation}

When the animals were pulling various loads to comprehensively monitor the effect of loads on donkeys' welfare, the behavioural occurrences were recorded as stress related to work. Time required to cover the distance of loaded donkeys was also measured.

\subsection{Heart Rate Measurement}

Heart rate measurement was used as a physiological response when animals were pulling loads. Measurement was also taken on donkeys (without any load) at resting state to serve as control group. Wireless heart beat sensor consisting of two main components-transmitter and wrist receiver [20] was used to measure heart rate. The sensor transmits heart beats of animals to the receiver. The transmitter was attached to an adjustable strap before mounting on the animals. To develop contact between the skin and the transmitter, the band should be moisten before fitting. To further facilitate contact and avoid interruption, a gel (Lectro Derm) was used on the belt and skin of the animals. The heart rate signals transmit usually telemetrically within a range of $1 \mathrm{~m}$ to the receiver, which was safely attached to the strap. The receiver had five sampling intervals: manual, R-R (beat to 
beat), $5 \mathrm{~s}, 15 \mathrm{~s}$ and $60 \mathrm{~s}$. Selection of intervals is chosen in a way that the memory could be utilized effectively. In this measurement, the receiver was set to $5 \mathrm{~s}$ intervals. The data stored in the receiver usually upload with PC interface unit. Heart beat sensors were mounted on the animals immediately before the start of loading to record the heart rate variations and dismounted after the trip is completed.

\subsection{Data Analysis}

The heart beat data stored in the receiver were uploaded with PC interference unit for analysis. Statistical analysis was conducted using SAS (version 9.4) software PC based programme. Analysis of variance (MANOVA), general linear model and regression analysis were used for data processing.

\section{Results}

Behavioural, physiological parameters and speed of working animals were the main responses used to evaluate their welfare.

\subsection{Behavioural Responses}

During pulling carts of various loads, some of the behaviours that most frequently occurred are illustrated in Table 1. The behaviours were load dependent and grossly fell into two main categories. When the loads were between $500 \mathrm{~kg}$ and $700 \mathrm{~kg}$, heavy and rapid panting, refuse to move forward and falling down were the behaviours that occurred mostly.

\subsection{Speed Versus Loads}

Animals' speeds and loads are illustrated in Fig. 1. It could be noted that speeds of donkeys were strongly influenced by the applied loads. When the load increased from $100 \mathrm{~kg}$ to $200 \mathrm{~kg}$, the average speed remained almost unchanged. As the loads increased to 300, 400 and $500 \mathrm{~kg}$, the corresponding mean speeds were $3.68,3.58$ and $3.5 \mathrm{~km} / \mathrm{h}$, respectively, denoting slow decline.

The speed further declined to $2.94 \mathrm{~km} / \mathrm{h}$ and 2.54 $\mathrm{km} / \mathrm{h}$ when the loads changed to $600 \mathrm{~kg}$ and $700 \mathrm{~kg}$, respectively. In this case, the speed decreased sharply and indicates that donkeys speed and the load applied to them are inversely correlated $(P<0.001)$. A polynomial function having the order of four fits well $\left(R^{2}=0.78\right)$ to the points.

Table 1 Load ranges and behavioural responses of working donkeys.

\begin{tabular}{ll}
\hline Load range $(\mathrm{kg})$ & Occurred behaviours \\
\hline $100-500$ & Aggressiveness, defecation, ear erecting, tail wagging, smelling and moving backward \\
$500-700$ & Heavy and rapid panting, refuse moving forward and falling down \\
\hline
\end{tabular}

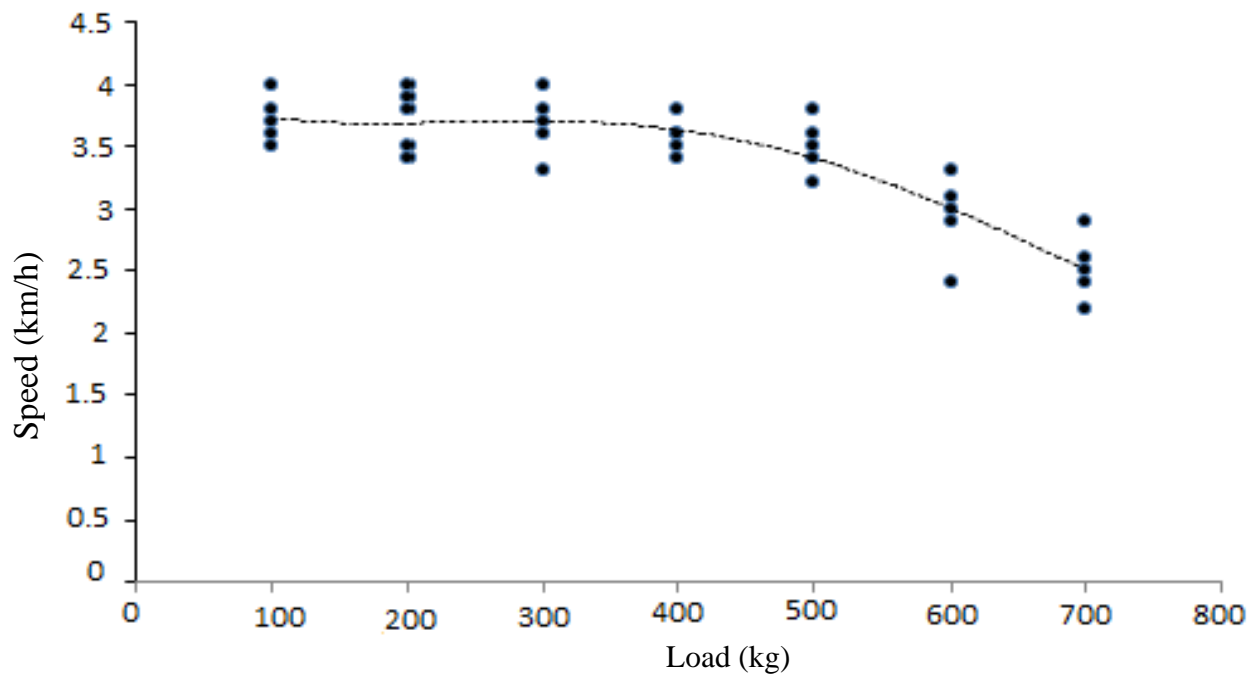

Fig. 1 Speed variation versus applied loads. 


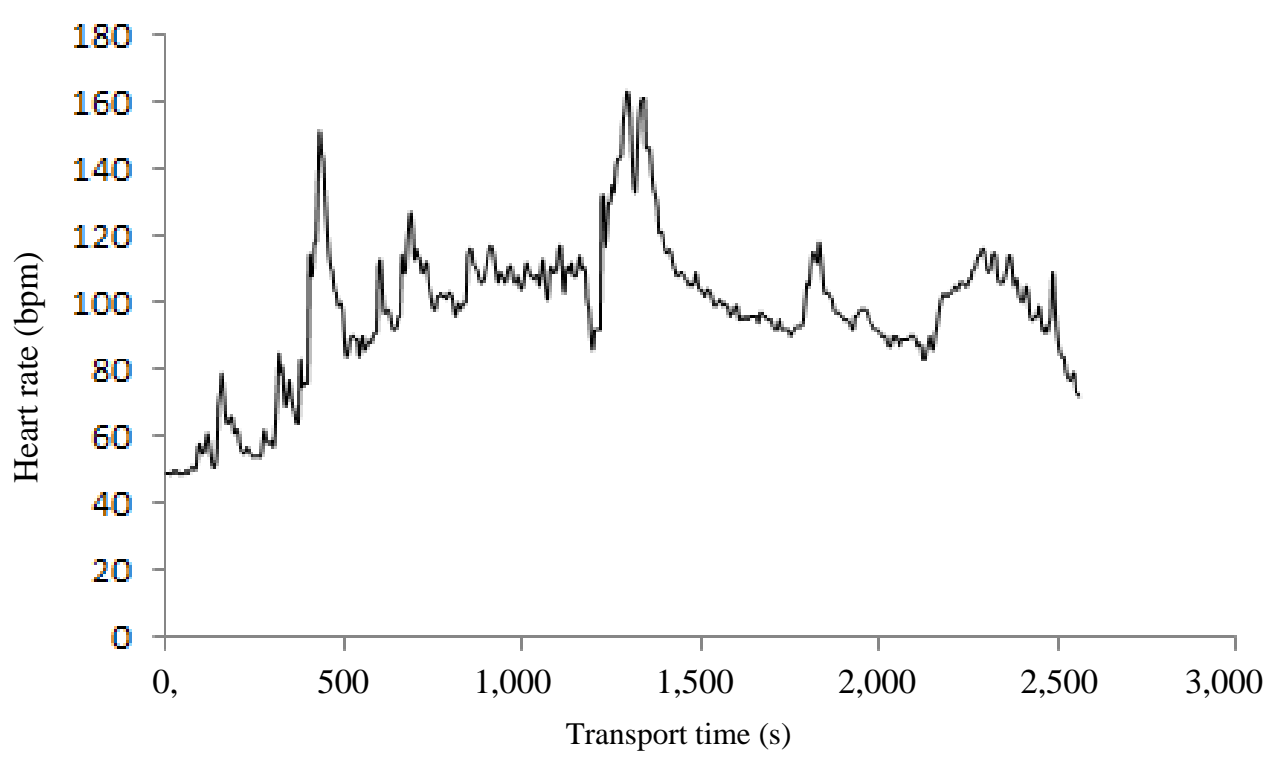

Fig. 2 Heart rate profile of donkey pulling two wheeled loaded cart.

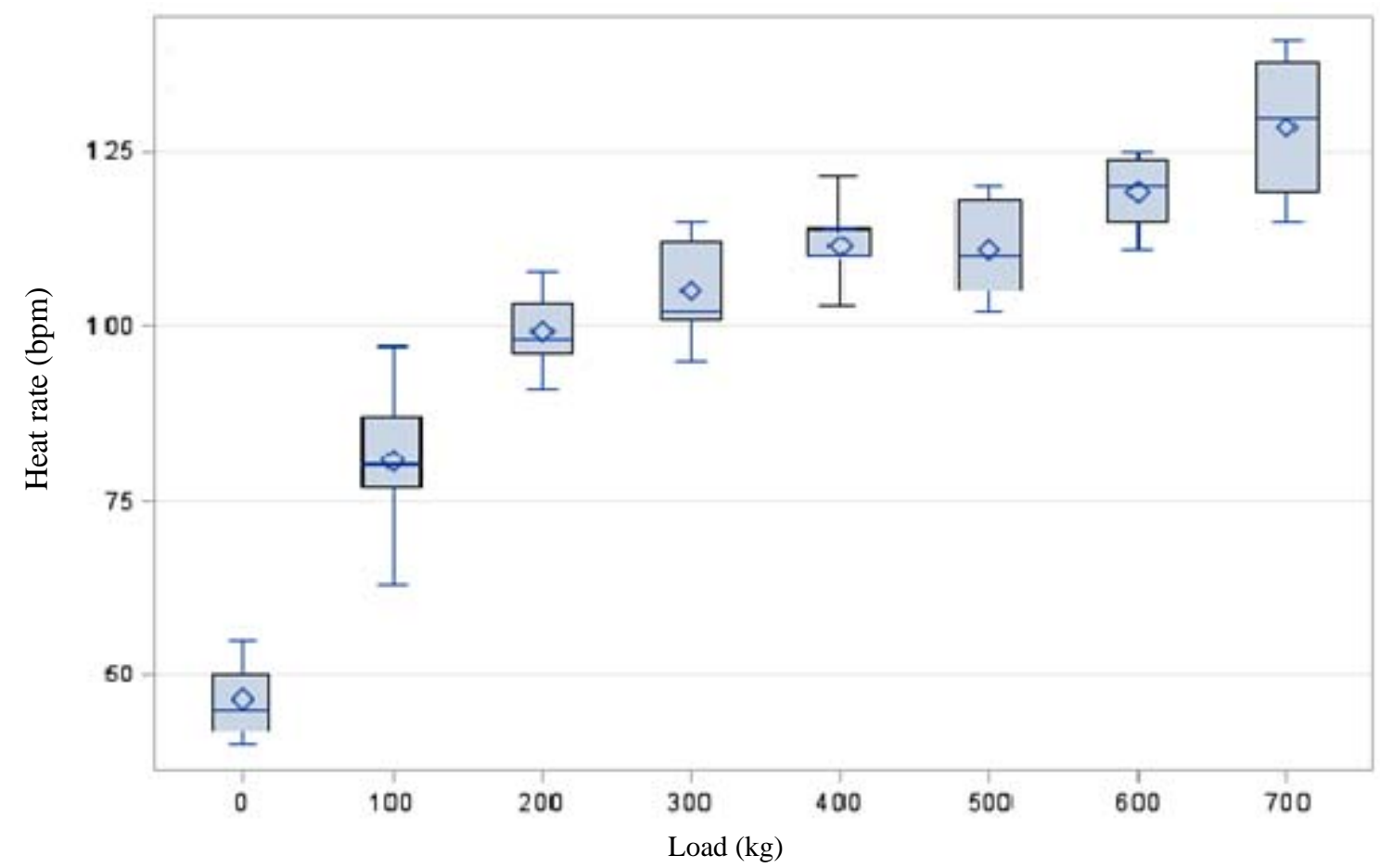

Fig. 3 Heart rate performances against various loads.

\subsection{Dynamic Heart Rate Profile}

Representative heart rate profile of donkey while pulling loaded carts is presented in Fig. 2. The donkey body weight was $154 \mathrm{~kg}$ and pulled a cart having a load of $400 \mathrm{~kg}$ for about $42 \mathrm{~min}$.

Rapid heart rate elevation was recorded shortly after resting state (49 bpm). It reached a peak of 151 bpm as a physiological response to the load, and this stage required about $7 \mathrm{~min}$. Thereafter, the pulse rate varied between 85 bpm and 162 bpm, with occasional peaks but fairly steady state with a mean of $100 \mathrm{bpm}$, and it consisted around $77.5 \%$ of the operation time. During unloading, heart rate of the animal started declining sharply from $109 \mathrm{bpm}$ to $72 \mathrm{bpm}$, but it 
would require some time to recover and reach the original resting state.

\subsection{Pulling Loads and Heart Rate Responses}

Heart rate growth against loads of working donkeys is illustrated in Fig. 3. There were various animal loads and heart rate responses, including a control group without any load. The heart rate mean at rest state is $46 \pm 6 \mathrm{bpm}$. The mean heart rate of loaded (100 kg) animals was $81 \pm 12 \mathrm{bpm}$ and $99 \pm 6 \mathrm{bpm}$ as the load increased to $200 \mathrm{~kg}$. It further elevated to 105 $\pm 8 \mathrm{bpm}$ as the load increased to $300 \mathrm{~kg}$. In this way, the heart rate kept on growing as the load increased by every $100 \mathrm{~kg}$ until the maximum load (700 kg), and the corresponding heart rate was $129 \pm 11 \mathrm{bpm}$. The results demonstrated that there was strong correlation between load and heart rate growth $(P<0.001)$. Moreover, the heart rate growth against load could be best described by a polynomial function of an order three $\left(R^{2}=0.907\right)$.

\section{Discussion}

\subsection{Behaviour and Speed}

Work related stress of the donkeys expressed in behavioural responses were load dependent and grossly fell in two categories. The displayed behaviours were aggressiveness, defecation, ear erecting, tail wagging, smelling and moving backward for loads between 100 $\mathrm{kg}$ and $500 \mathrm{~kg}$. When loads exceeded $500 \mathrm{~kg}$, heavy and rapid panting, refuse moving forward and falling down were the most occurred behaviours. Behavioural responses are the first line of defense to environmental challenges, and stress responses in donkeys are always conducted on the basis of irregular behavioural phenomena. In donkeys, signs of fatigue include unwillingness to continue, uncoordinated legs and excitement after work, and continuous working causes them increased stress [7, 21].

The displayed behaviours are not common under ordinary environment and they occurred as the consequence of the applied loads. As the load increased to $600 \mathrm{~kg}$ and $700 \mathrm{~kg}$, the animals refused to move, fell down and panted heavily and rapidly. Thus, this indicated that behaviours were affected by magnitude of the load. In particular, heavy loads that exceed $500 \mathrm{~kg}$, the related behaviours had a serious impact on welfare of the animals.

Speed of the animals was in the range of $3.68 \mathrm{~km} / \mathrm{h}$ (at $100 \mathrm{~kg}$ ) and $2.54 \mathrm{~km} / \mathrm{h}$ (at $700 \mathrm{~kg}$ ), therefore the highest speed at the minimum load and the lowest speed at the maximum load. It is recommended 4 $\mathrm{km} / \mathrm{h}$ speed and $6 \mathrm{~h}$ working time a day for a donkey weighing 200-300 kg and carrying 25-70 kg [22]. During ploughing experiment using a single donkey with heaviest, heavier and light ploughs, the corresponding speeds are 2.67, 2.84 and $2.98 \mathrm{~km} / \mathrm{h}$, respectively [23].

There are similar findings on animals' workload and displayed behaviour. Heart rate is generally regarded as a reliable indication of workload and correlates reasonably well with stepping rate, speed and power [24].

The speed of the animals started to decline successively from $500 \mathrm{~kg}$ to $700 \mathrm{~kg}$ loads, and this was a sign of fatigue, indicating that welfare of the animals was affected. If owners disregard this behaviour and continue working with the animal, more serious consequence could occur.

Stress responses in donkeys are always conducted on the basis of irregular behavioural phenomena that may be difficult to interpret [25, 26]. Under this condition, donkeys are subjected to different stressors, which may compromise their health and consequently result in poor performance [27]. Stress generally affects the host defense system and increases its susceptibility to infections [28]. The different conditions, by which donkeys are subjected to, are improper housing and handling that expose them to wounds and infection mostly during the hot-dry and rainy seasons [11]. Besides, donkeys need supplements, especially throughout the dry season, when they are increasingly used for traction [29]. 


\subsection{Heart Rate}

The measurement was conducted in April and temperature and relative humidity were $15-25{ }^{\circ} \mathrm{C}$ and about $60 \%$, respectively. Heart rate of control animals was $46 \pm 6 \mathrm{bpm}$ at resting state. During mean daily meteorological data $\left(31.20 \pm 0.27{ }^{\circ} \mathrm{C}, 74.80 \% \pm\right.$ $1.44 \%$ ), the mean heart rate of pack donkey was 52.67 $\pm 2.40 \mathrm{bpm} \mathrm{[26];} \mathrm{it} \mathrm{is} \mathrm{higher} \mathrm{heart} \mathrm{rate} \mathrm{than} \mathrm{control}$ animals and it may be due to temperature and relative humidity differences.

Donkey heart rate is stress quantifiable parameter used to define stress level under continuous work, and the standard range is $H_{0}+(15-45) \mathrm{bpm}$, where $H_{0}$ is the heart rate at rest [30]. According to the author under work condition, the growth of heart rate should be in the range of 15-45 bpm. During the experiment depending upon the load, rapid heart rate growth was recorded with the highest at $129 \pm 11 \mathrm{bpm}$. In respect to resting state, the heart rate of working animals was elevated by a factor of up to 3. It is evident that work is stressful to donkeys that can not be avoided. However, the central question is to what extend should the animals be exposed to work stress without their welfare being compromised. In this regard, it is stated that the standard stress ranges are $H_{0}+(15-45)$ bpm [30]. But the recorded measurements were greater than what are recommended by the author, i.e., (46 \pm 6$) b p m+(81 \pm 12) b p m$ to $(46 \pm 6) b p m+(129$ \pm 11 ) bpm. Despite short working hours (30-40 min), the heart rate exceeded the recommended ranges. Therefore, it clearly indicates that they were under stressful condition. The average heart rate of two donkeys at maximum exercise was $223 \pm 2 \mathrm{bpm}$, representing a fivefold increase over the pre-exercise heart rate value [31].

During pulling carts of various loads, the displayed behaviours, working speed and heart rate of the donkeys jointly provided a picture on the stress level of the animals. It can be concluded that at loads between $500 \mathrm{~kg}$ and $700 \mathrm{~kg}$, the speed sharply declined to from $3.5 \mathrm{~km} / \mathrm{h}$ to $2.5 \mathrm{~km} / \mathrm{h}$. Besides, at these loads, they displayed behaviours, like refuse to move, heavy and rapid panting and falling down, and these illustrated very stressful condition. In the meantime in respect to resting state, the heart rate elevated from 2.4 times up to 3 times.

\section{Conclusions}

Alteration of walking speed of load pulling donkey was key behavioural indicator, as it is inversely correlated with load, and donkey owners or operators have to be observant to the speed and react accordingly to not compromise welfare of the working animal.

While pulling a load on two different wheeled cart, the relationships between load and donkey's welfare was influenced by a number of factors. As the load exceeded $400 \mathrm{~kg}$, the speed declined significantly. The behavioural observation confirmed that animals were showing heavy panting and falling down. This leads to the conclusion that animals could pull about 2.7 times of their live weight.

However, if the animal is subjected to continuous and long working hours (about $6 \mathrm{~h}$ ), it is recommended to keep the load about double of its live weight so as to safeguard the animal's welfare.

\section{References}

[1] Food and Agriculture Organization (FAO). 1997. "Donkey and Other Livestock Figures." FAOSTATS. Accessed February 14, 2016 http://apps.fao.org/cgi-bin/nph-db.pl?subset=agriculture.

[2] Starkey, P., and Starkey, M. 2004. "Regional and World Trends in Donkey Populations.” In Donkeys, People and Development, edited by Fielding, D., and Starkey, P. Wageningen, The Netherlands: ACP-EU Technical Centre for Agricultural and Rural Cooperation (CTA), 244-71.

[3] Starkey, P. 2000. "The History of Working Animals in Africa." In The Origins and Development of African Livestock: Archaeology, Genetics, Linguistics and Ethnography, edited by Blench, R. M., and MacDonald, K. London, UK: University College London Press, 478-502.

[4] Wilson, T. R. 1991. "Equines in Ethiopia.” In Donkeys, Mules and Horses in Tropical Agricultural Development, 
edited by Fielding, D., and Pearson, R. A. UK: Centre for Tropical Veterinary Medicine and School of Agriculture, University of Edinburgh, 33-47.

[5] Inns, F. M. 1980. "Animal Power in Agricultural Production Systems with Special Reference to Tanzania.” World Animal Review 34: 2-10.

[6] Nenogomasha, E. M., Pearson, R. A., and Wold, A. G. 1999. "Empowering People through Donkey Power into the Next Millennium.” In Proceedings of ATNESA/SANAT International Workshop on Empowering Farmers with Animal Traction into the 21st Century, 22-31.

[7] Pal, Y., Kumar, S., and Gupta, A. K. 2002. "Blood Gases, Acid-Base and Physiological Indices in Donkeys as Pack Animals.” Draught Anim. News 37: 27-33.

[8] Martin, C. M., and Smith, D. G. 2005. "The Impact of Donkey Ownership on Livelihoods of Female Peri-urban Dwellers in Ethiopia.” Trop. Anim. Health Prod. 37: 67-86.

[9] Smith, D. J., and Pearson, R. A. 2005. “A Review of the Factors Affecting the Survival of Donkeys in Semi-arid Regions of Sub-Saharan Africa.” Trop. Anim. Health Prod. 37: 1-19.

[10] Martin-Curran, M., Feseha, G., and Smith, G. 2005. “The Impact of Access to Animal Health Services on Donkey Health and Livelihoods in Ethiopia.” Trop. Anim. Health Prod. 37: 47-65.

[11] Asha, M. E., Salim, M. O., Amel, O. B., and Ibrahim, A. A. 2006. "The Aerobic Bacteria of Equine Wound Infection Associated with Type of Animal Use and Sampling.” Sudan J. Vet. Sc. Anim. Husb. 45 (1-2): 1-7.

[12] De Aluja, A. S. 1998. "The Welfare of Working Equids in Mexico.” Applied Animal Behaviour Science 59 (1-3): 19-29.

[13] Pritchard, J. C., Lindberg, A. C., Main, D. C. J., and Whay, H. R. 2005. “Assessment of the Welfare of Working Horses, Mules and Donkeys, Using Health and Behaviour Parameters." Preventative Veterinary Medicine 69 (3-4): 265-83.

[14] Tesfaye, A., and Martin-Curran, M. 2005. "A Longitudinal Survey of Market Donkeys in Ethiopia.” Trop. Anim. Health Prod. 37: 87-100.

[15] Burn, C. C., Dennison, T. L., and Whay, H. R. 2010. "Environmental and Demographic Risk Factors for Poor Welfare in Working Horses, Donkeys and Mules in Developing Countries.” The Veterinary Journal 186 (3): 385-92.

[16] Pearson, R. A. 1985. "Physiological Changes Associated with Work: Some Lessons from the Horse." In Proceedings of the International Workshop on Draught Animal Power for Production, 51-6.

[17] Rautaray, S. K. 1987. "Work Output of Bullocks during
Field Operations on Black Soils.” In Proceedings of the National Seminar on the Status of Animal Energy Utilisation, 69-87.

[18] Dawkins, M. S. 2006. “A User’s Guide to Animal Welfare Science.” Trends in Ecology and Evolution 21 (2): 77-82.

[19] Durham, A. E., Phillips, T. J., Walmsley, J. P., and Newton, J. R. 2003. "Study of the Clinical Effects of Post-operative Parenteral Nutrition in 15 Horses." Vet. Rec. 153 (16): 493-8.

[20] Ayo, J. O., Oladele, S. B., Ngnam, S., Fayomi, A., and Afolayan, S. B. 1999. "Diurnal Fluctuations in Rectal Temperature of the Red Sokoto Goat during the Harmattan Season.” Res. Vet. Sc. 66 (1): 7-9.

[21] Polar Electro Oy. 1995. Polar Vantage NV Manual.

[22] Jones, P. 1997. Donkeys for Development. Louis Trichardt, Northern Province, South Africa: H \& W Printers.

[23] Gebresenbet, G., and Kaumbutho, P. G. 1977. "Comparative Analysis of the Field Performances of a Reversible Animal-Drawn Prototype and Conventional Mouldboard Ploughs Pulled by a Single Donkey.” Soil and Tillage Research 40 (3-4): 169-89.

[24] O’Neill, D. H., and Kemp, D. C. 1989. “A Comparison of Work Outputs of Draught Oxen.” Journal of Agricultural Engineering Research 43: 33-44.

[25] Minka, N. S., and Ayo, J. O. 2007. "Effect of Shade Provision on Some Physiological Parameters, Behaviour and Performance of Pack Donkeys (Equus asinus) during the Hot-Dry Season.” Journal of Equine Veterinary Science 18 (2): 39-46.

[26] Ayo, J. O., Dzenda, T., and Zakari, F. O. 2008. "Individual and Diurnal Variations in Rectal Temperature, Respiration and Heart Rate of Pack Donkeys during the Early Rainy Season.” Journal of Equine Veterinary Science 28 (5): 281-8.

[27] Gupta, A. K., Mamta, Y. P., and Yadav, M. P. 1999. "Effect of Feed Deprivation on Biochemical Indices of Equids.” Journal of Equine Veterinary Science 10 (2): 33-8.

[28] Von Borell, E. H. 2001. "The Biology of Stress and Its Application to Livestock Housing and Transportation Assessment.” Journal of Animal Science 79: 260-7.

[29] Olaifa, F., Ayo, J. O., Ambali, S. F., Rekwot, P. I., and Minka, N. S. 2013. "Rectal Temperature Responses of Donkeys Administered with Ascorbic Acid and Subjected to Load-Carrying (Packing) during the Harmattan Season in Nigeria.” Trop. Anim. Health Prod. 45 (2): 473-7.

[30] Singh, G. 2000. "Empowering Farmers through Animal Traction in India.” In Proceedings of ATNESA/SANAT International Workshop on Empowering Farmers with Animal Traction into the 21st Century, 279-90. 
[31] Mueller, P. J., Jones, M. T., Rawson, R. E., Van Soest, P. J., and Hintz, H. F. 1994. "Effect of Increasing Work
Rate on Metabolic Responses of the Donkey (Equus asinus).” Journal of Applied Physiology 77 (3): 1431-8. 